\title{
A GEOGRAFIA CLÁSSICA NO BRASIL: breves considerações
}

\author{
Jéssica da Silva Costa \\ Gerson Gomes do Nascimento \\ gerson.nascimento@ifrn.edu.br \\ DOI: doi.org/10.15628/geoconexoes.2019.8747
}

\section{RESUMO}

O presente artigo foi desenvolvido a partir da análise do pensamento da geografia clássica, com a finalidade de articular suas teorias no processo de evolução do pensamento geográfico brasileiro, levando em consideração a realidade social do país. Nesse percurso, a geografia vai se fragmentar para atender os preceitos científicos da época, tornando-se, em seguida, Regional contemplando, desse modo, a relação homem-meio. Diante dessa perspectiva, a geografia brasileira surge no cenário de evolução da geografia mundial, enfrentando as dificuldades não apenas locais, mas em uma esfera internacional. No entanto, com todos os obstáculos, o Brasil consegue implantar o curso de geografia nas universidades e, assim, surgem os primeiros estudos de geografia no Brasil.

Palavras chave: Geografia clássica; Pensamento geográfico; Brasil.

\section{ABSTRACT}

This article was developed from the analysis of classical geography thinking, with the purpose of articulating its theories in the process of evolution of Brazilian geographic thought, taking into account the social reality of the country. In this course, the geography will fragment to meet the scientific precepts of the time, becoming Regional then contemplating the relationship between man and environment. Given this perspective, the Brazilian geography appears in the scenario of evolution of the world geography, facing the difficulties not only local, but in an international sphere. However, with all the obstacles, Brazil manages to implement the course of geography in the universities and, thus, the first studies of geography in Brazil appear.

Keywords: Classical geography; Geographical thought; Brazil.

\section{INTRODUÇÃO}

A geografia, enquanto ciência do homem e da natureza se faz responsável pelos estudos que cercam os fenômenos naturais e sociais tentando explicar, em sua trajetória, os impactos da relação homemmeio. Entretanto, essa relação se altera ao longo do tempo e, com isso, a ciência vai acompanhando esse processo de transformação.

O conhecimento geográfico já era algo obsoleto, contudo sua sistematização enquanto ciência se configurou tardiamente no período que compreende o final do século XVII e início do século XIX 
na Alemanha, país onde a ciência geográfica é iniciada partindo dos estudos dos intelectuais Carl Ritter (1779 - 1859) e Alexander Von Humboldt (1759 - 1859). Esse percurso do desenvolvimento da geografia vai passar por várias etapas até chegar a geografia que temos hoje.

Este artigo apresenta o pensamento clássico da geografia contextualizando com o pensamento geográfico brasileiro. Essa reflexão apresenta como eixo principal a ambientação histórica da geografia enquanto ciência no Brasil. Para o desenvolvimento do artigo, fez-se o uso de conceitos apoiados nos autores Moreira (2009 e 2011) e Andrade (2008).

\section{O PENSAMENTO CLÁSSICO NO CONTEXTO HISTÓRICO DO PENSAMENTO GEOGRÁFICO BRASILEIRO}

A ciência geográfica surge na perspectiva da realidade social de cada país, bem como da necessidade de interpretação da natureza. Diante disso, a geografia clássica contribui de forma direta para exploração de territórios dominados pela burguesia, tais contribuições eram moldadas de acordo com as condições econômicas e sociais de cada país. Em decorrência deste processo, a geografia acabou se fragmentando em escolas nacionais ou regionais para atender de forma individual às necessidades de desenvolvimento das diversas localidades. É nessa concepção que surgem as escolas alemã, francesa, norte-americana, britânica e russa, com o propósito de promover estudos de interesses particulares.

Entretanto, o processo que antecede o surgimento das "escolas geográficas" percorre um decurso de subdivisão, que por sua vez é nitidamente visível no contexto social do século XIX, com a divisão técnica do trabalho trazida pela Revolução Industrial, que segmenta o trabalho, "o pensamento e a sociabilidade exaustivamente, a começar pela fragmentação do conhecimento numa diversidade infinita de formas de ciências". (Moreira, 2011.). É nesse contexto que a geografia se encaminha para divisão de seus estudos, assim como outras ciências. Mas, o que move esse desmembramento é a possibilidade da ciência matemática não se sustentar dentro de outras ciências. Sendo assim,

\footnotetext{
Teme-se que sem o parâmetro matemático uma ciência rigorosa por fim não se sustenta. [...] A solução vem, por fim, na forma de um duplo tipo de legalidade: a matemática para a esfera de tratamento científico da natureza e a institucional para esfera do tratamento científico do homem. Nascem as Ciências Naturais e Ciências Humanas. (MOREIRA, 2011, p. 17).
}

É nessa perspectiva que, na virada do século XIX - XX surge a geografia física com os estudos em geomorfologia, climatologia e biogeografia, e a geografia humana que, por sua vez, vai desenvolver estudos nas áreas de urbana, agrária, economia e população. E, por muito tempo, a geografia seguiu por diferentes vertentes, em um âmbito um tanto quanto radical, como se os estudos humanos e físicos não dependessem um do outro, desenvolveram-se estudos e pesquisas isoladas. Diante dessa separação da ciência geográfica, observou-se a exploração de "conteúdos vazios", onde homem e espaço não se envolvem. 
Partindo da interação do homem com o espaço, manifesta-se a necessidade de estudos onde a geografia humana completasse a geografia física, ou seja, uma compondo a outra, sendo apenas uma só Geografia. Mediante essa esfera de mudanças e transformação no processo de evolução da ciência geográfica, forma-se a Geografia Regional.

\begin{abstract}
E no âmbito unitário, vai por fim, conhecer o formato com que o discurso da Geografia clássica mais vai se tornar conhecida, o da Geografia Regional, e o formato com que também se difunde e produz os seus melhores frutos, o da Geografia homem-meio, aqui designados de Geografia da Civilização. A Geografia Regional se forma, e afirma a Geografia clássica, no discurso da região como unidade do físico e do humano. (MOREIRA, 2011, p. 20).
\end{abstract}

O discurso que contempla a relação do homem com o meio é o que podemos chamar de Geografia das Civilizações, são intelectuais como Ratzel, na Alemanha, Reclus e Vidal de La Blache, na França, Marsh e Sauer, nos Estados Unidos, alguns dos pensadores da Geografia clássica, de onde caminha a essência das grandes matrizes.

Nesse primeiro momento da Geografia clássica, os estudos serão pautados partindo de duas correntes de pensamento, a do possibilismo e a do determinismo, conceitos aplicados como seguimentos do pensamento geográfico para explicar o elo natureza-homem.

Portanto, a teoria do determinismo geográfico de Fredrich Ratzel (1844 - 1904) considera que as condições naturais são o que determina a vida em sociedade, logo o homem seria o produto do meio, servo do seu próprio espaço. Já o possibilismo geográfico desenvolvido por Paul Vidal de La Blache (1845 1918) trata-se de uma ideia oposta ao determinismo, donde o possiblismo defende que o homem também é transformador do meio onde vive, havendo inúmeras possibilidades para ação humana, de modo a não obedecer à relação causa e efeito. Essas duas correntes do pensamento geográfico estarão presentes em vários contextos de aplicabilidade da geografia, inclusive as principais escolas geográficas que surgem na Alemanha, França, Estados Unidos, Inglaterra e Rússia desenvolvem seus estudos com tendências mais direcionadas para uma dessas teorias, buscando sempre atender a realidade de cada país.

A aplicabilidade dos conceitos da ciência geográfica se molda conforme interesses sociais e econômicos de um determinado grupo, nesse caso especificamente a burguesia. É partindo dessa afirmativa que surge o Brasil no contexto da colonização.

Os séculos XV e XVI presenciariam a intensificação das grandes navegações, com o descobrimento do caminho marítimo para as Índias, descobrimento e a conquista da América e o início da navegação no Oceano Pacífico, que seria intensamente explorado no século XVII. (CORRÊA, 2008, p.58).

A geografia dessa época concentrava-se na conquista e exploração de novos territórios, tais excursões eram custeadas pela alta burguesia, soberanos de países europeus como: Portugal, Espanha, 
França, Holanda e Inglaterra. A ambição por maiores riquezas era o que movia cada um desses países que cresceu por meio do desenvolvimento do comércio e exploração de territórios estrangeiros.

É nesse contexto que o Brasil se torna colônia de Portugal, nesse primeiro momento a geografia contribui no âmbito da descoberta dos novos espaços, exploração e dominação dos povos nativos, assim caracterizando a primeira fase do capitalismo (capitalismo comercial). Então, à medida que o território brasileiro cresce e expande, o espaço ganha novas formas, pois o que era apenas uma terra com vastas matas e sua população nativa passa a ser uma grande colônia de exploração.

Como toda rica colônia de exploração, o Brasil passa por um processo de habitação e, consequentemente, a expansão populacional, esse crescimento vai demandar habitação e condição social para população, é em tais circunstâncias que a geografia brasileira nasce clássica, no sentido de uma geografia regional, onde a unidade do físico e humano se completa, entretanto, ainda não sendo uma geografia puramente brasileira, pois havia muito da visão europeia, visto que sua origem se dá no "quadro da geografia mundial, dela incorporando seu referencial teórico, mas passando ao largo dos seus problemas". (Moreira, 2009.).

O período que compreende a década de 1950 é o marco que separa o antes e o depois da geografia puramente brasileira, o que antes era apenas a percepção estrangeira, onde

\footnotetext{
Toda uma literatura e uma icnografia voltadas para descrição e esboço de classificação, distribuição e localização das paisagens brasileiras vão de acumulando no tempo com a propriedade de, embora em geral vazada no olhar do europeu - só na segunda metade do século XIX a literatura ganha forma e a linguagem portuguesa uma sintaxe nacional, [...] (MOREIRA, 2009, p.30).
}

Passou a ter mesmo que timidamente, mas ainda sim um pensamento próprio, partindo não mais de uma autentica visão estrangeira, desse modo consolidando o solo epistemológico da Geografia brasileira. Embora o curso de geografia tenha sido implantado na universidade nos anos de 1930 e 1940, somente em 1950 inicia a primeira geração de geógrafos formados no Brasil, iniciando-se de fato a história da geografia brasileira.

Nos anos que seguem, grandes geógrafos brasileiros ganham destaque no cenário mundial, em meados do século XX, Aziz Nacib Ab'Saber (1924-2012) elabora estudos que tratam a estreita relação entre os elementos da natureza com a sociedade. Nos anos de 1960 e 1970, Aziz Ab'Saber foi considerado um dos principais cientistas brasileiros, com a publicação de diversos trabalhos. Outro geógrafo brasileiro que tem reconhecimento internacional é Milton Santos (1926 - 2001), tendo como um dos seus principais estudos a noção do "meio técnico cientifico informacional". Mesmo que o pensamento geográfico tenha se desenvolvido de forma tardia no Brasil, esse percurso alavancou vários estudiosos da geografia brasileira. 


\section{CONSIDERAÇÕES FINAIS}

A geografia tem sua trajetória marcada como o conhecimento responsável por arquitetar guerras e explorar territórios, mediante interesses da burguesia, tais percursos foram essenciais para o reconhecimento da geografia como ciência. Dentro desse processo a geografia passou por várias fases, mas sempre contribuindo de forma direta na construção de novos espaços, explorados ou reconstruídos para atender necessidades de uma elite dominante. Dessa forma, o que temos hoje em termos de avanços no campo dessa ciência só vem justificar o quanto essa se transformou ao longo do tempo bem como seu poder de alcance frente à realidade estabelecida.

\section{REFERÊNCIAS}

1. ANDRADE, Manoel Correia de. Geografia: ciência da sociedade. Recife: Ed. Universitária da UFPE, 2008.

2. MOREIRA, Ruy. $\mathbf{0}$ pensamento geográfico brasileiro, vol. 1: as matrizes clássicas originárias. São Paulo: Contexto, 2011.

3. MOREIRA, Ruy. 0 pensamento geográfico brasileiro, vol. 2: as matrizes da renovação. São Paulo: Contexto, 2009. 